GRADIATION\&APPLICATIONS

ISSN 2466-4294 (online) | rad-journal.org

Vol. 2 | Issue 2 | pp. 124-128, 2017

doi: 10.21175/RadJ.2017.02.026

Original research paper

\title{
NEUTRON ACTIVATION TECHNIQUE: A RELIABLE TOOL TO DETERMINE THE MINERAL COMPOSITION IN AGRO-INDUSTRIAL PRODUCTS*
}

\author{
Maria Ângela de B. C. Menezes ${ }^{1,2^{* *}}$, Ana Clara Oliveira Pelaes ${ }^{1}$, \\ Paula Maria Borges de Salles ${ }^{2}$, Wellington Ferrari da Silva ${ }^{2}$, \\ Rodrigo Reis de Moura ${ }^{2}$, Igor Felipe Silva Moura ${ }^{2}$, Radojko Jaćimovićc
}

${ }^{1}$ Nuclear Technology Development Centre, Brazilian Commission for Nuclear Energy (CDTN/CNEN), Division for Analytical Techniques, Laboratory for Neutron Activation Analysis, Belo Horizonte, Brazil ${ }^{2}$ Federal University of Minas Gerais (UFMG), Department of Nuclear Engineering, Belo Horizonte, Brazil 3Jožef Stefan Institute, Department of Environmental Sciences, Ljubljana, Slovenia

\begin{abstract}
Mineral composition analysis in agro industrial products is necessary for several reasons, such as the determination of nutritious value, assessment of product quality, detection of adulteration, compliance with legal and labelling requirements, food forensic, research and development. It is important to enhance that a variety of toxic elements in food has been increasing as a consequence of new agricultural practices, industrial development, and environmental pollution. For that, analytical techniques are expected to play a crucial role on chemical elemental concentration determination. In this paper, the neutron activation technique was applied by means of $k_{0^{-}}$ standardized method. This method uses neutron flux monitors, spectral parameters of the nuclear reactor, gamma system counter absolutely calibrated and $k_{o}$ constants and not standards of chemical elements, as in relative method. Several agro-industrial samples and one soil sample were analysed using the $100 \mathrm{~kW}$ TRIGA Mark I research reactor. Therefore, the objective of this paper was to show the versatility and the efficiency of this technique on multielemental concentration determination in diversified matrices, showing that several chemical elements were determined with a large range of elemental concentration. Reference materials were also analysed and evaluated statistically, pointing out the reliability of the technique.
\end{abstract}

Key words: Agro-industrial products, elemental composition, $k_{o}-I N A A$, neutron activation analysis

\section{INTRODUCTION}

The quality of food consumed daily strongly influences the human health and life quality. Year after year, great attention has been paid to food quality.

The interest and care about safe agro industrial products has been growing. One of food technology sector major priorities is to fulfil high-quality criteria. The development and optimization of monitoring and control methods of agro industrial production, including field production, food materials, and their processing show its concern $[1,2]$.

According to the development of human knowledge in several fields - nutrition, food chemistry, food microbiology, food analysis - the requirements for quality have been diversified. The nutrition quality is indicated by the composition of nutrients, including essential elements. The chemical elements present in agro-industrial food may come from the plantation field, from processing, storage and transportation [2].
It means that raw material influences the quality of food as well as the technological procedure used.

Mineral composition analysis in agro industrial products is necessary for several reasons, such as the determination of nutritious value [2], assessment of product quality [3], detection of adulteration [4], compliance with legal and labelling requirements [5], food forensic [6], research and development [7]. It is important to enhance that a variety of toxic elements in food has been increasing as a consequence of new agricultural practices, industrial development and environmental pollution. For that reason, analytical techniques are expected to play a crucial role in chemical elemental concentration determination.

Various analytical techniques are applied to provide the elemental concentration information like X-ray fluorescence spectrometry [8], AAS [9], ICP-OES [10], ICP-MS [11], among others. At present, atomic spectrometry techniques and ICP-MS (Inductively coupled plasma mass spectrometry) are the most used techniques to determine elemental composition in food

\footnotetext{
* The paper was presented at the Fifth International Conference on Radiation and Applications in Various Fields of Research (RAD 2017), Budva, Montenegro, 2017.

menezes@cdtn.br
} 
M. Â. de B. C. Menezes et al., Neutron activation technique..., Rad. Applic., 2017, 2, 2, 124-128

samples. ICP-MS is usually preferred due to its multielemental capability and the low limits of detection for most elements. However, these techniques usually involve sample preparation procedures for the total destruction of the solid matrix by means of a previous chemical treatment. These procedures are usually a tedious, expensive and laborious wet digestion steps and the possible analyte losses and/or sample contamination. Due to these constraints, the use of other methodologies for direct analysis of solid samples represents an advantage. Among them, there are X-ray fluorescence spectrometry (XRF) and neutron activation technique [12-20]. They are multielemental analysis that can be directly carried out on solid samples [21].

In this study, the technique of neutron activation analysis was applied, $k_{0}$-standardized method [13-20, 22] to several agro-industrial products to show its reliability to determine several elements in diversified matrices. In order to complete the study, one soil sample was also analysed, once it was intrinsically linked to agro products.

\section{NEUTRON ACTIVATION ANALYSIS}

Neutron activation analysis is based on the irradiation of a sample with neutrons in a nuclear reactor to produce specific radionuclides. After the irradiation, the characteristic gamma rays emitted by the decaying radionuclides are quantitatively measured by the semiconductor detector. Based mainly on such information, the concentration calculation is obtained.

In this paper, the technique was applied by means of $k_{0}$-standardized method, that uses neutron flux monitors, spectral parameters of the nuclear reactor, gamma system counter absolutely calibrated and $k_{0}$ constants and not standards of chemical elements, as in relative method [23].

Unlikely the relative method, the $k_{0}$ method requires very rigorous calibration of input quantities including the thermal, epithermal and fast neutron fluence rates and gradients in the irradiation position. It is also required the full-energy photopeak efficiency determination and the coincidence counting effects determination. Therefore, the $k_{0}$-standardization method transforms NAA to a highly effective and competitive determination method. Thus, the concentration $\left(\rho_{a}\right)$ of an analyte " $a$ ", or chemical element, is obtained from its measured isotope gamma ray as [23]:

$$
\rho_{s}=\frac{\left(\frac{N_{p} / t_{m}}{S D C W}\right)_{a}}{\left(\frac{N_{p} / t_{m}}{S D C w}\right)_{A u}} \times \frac{1}{k_{0, A u}(a)} \times \frac{G_{t h, A u} f+G_{e, A u} Q_{0, A u}(\alpha)}{G_{t h, a} f+G_{e, a} Q_{0, a}(\alpha)} \times \frac{\varepsilon_{p, A u}}{\varepsilon_{p, a}}
$$

where " $A u$ " refers to the co-irradiated gold monitor [197 $\left.\mathrm{Au}(\mathrm{n}, \gamma)^{198} \mathrm{Au}, \mathrm{E} \gamma=411.8 \mathrm{keV}\right]$ and $N_{p}$ is the net number of counts in the full-energy peak (corrected for pulse losses), $W$ is the mass of the sample, $w$ is the mass of the gold monitor, $t_{m}$ is the measuring time, $S=1-\exp \left(-\lambda t_{\text {irr }}\right), \lambda$ is the decay constant, $t_{\text {irr }}$ is the irradiation time, $D=\exp \left(-\lambda t_{d}\right)$, $t_{d}$ is the decay time, $C=\left(1-\exp \left(-\lambda t_{m}\right)\right) /\left(\lambda t_{m}\right), f$ is the thermal to epithermal neutron fluence rate ratio, $Q_{o}=I_{o} / \sigma_{o}$ (resonance integral to $2200 \mathrm{~m} \mathrm{~s}^{-1}$ cross-section ratio), $\alpha$ is the measure for the epithermal neutron fluence rate distribution, approximated by a $1 / E^{1+\alpha}$ dependence (considered to be independent from neutron energy), and $\varepsilon_{p}$ is the full-energy peak detection efficiency. $G_{t h}$ and $G_{e}$ are factors for correction of thermal and epithermal neutron self-shielding, respectively.

In Eq. (2), the $k_{0, A u}$ is defined as:

$$
k_{0, A u}(a)=\frac{M_{A u} \theta_{a} \sigma_{0, a} \gamma_{a}}{M_{a} \theta_{A u} \sigma_{0, A u} \gamma_{A u}}
$$

where $M$ is the atomic mass, $\theta$ is the isotopic abundance, $\sigma_{o}$ is the $2200 \mathrm{~m} \mathrm{~s}^{-1}(\mathrm{n}, \gamma)$ cross-section, and $\gamma$ is the absolute gamma-ray intensity (emission probability). The $k_{0, A u}$ is a constant experimentally measured and published in reference literatures [24, 25] and is independent from neutron spectrum. The first and forth factors in Eq. (1) are related to detection parameters involved in activity determination by gamma-ray spectrometry, including both the radionuclide of interest (index $a$ ) and comparator (index $A u$ ). The second factor is $k_{0}$-factor and the third factors are related to parameters involved with neutron field characteristics of irradiation channel ( $f$ and $\alpha$ ) and $Q_{o}(\alpha)$. The $k_{0}$-based standardization method assumes that spectral parameters $f$ (thermal-to-epithermal fluence rate ratio) and $\alpha$ (deviation from $1 / \mathrm{E}$ distribution of epithermal neutrons) are well known and constant during irradiation.

For the gamma-ray spectroscopy, the curves of detector efficiency are previously experimentally measured at specific counting positions using calibrated radioactive point sources.

\section{EXPERIMENTAL}

\subsection{Agro-industrial samples}

Diversified agro industrial samples were analysed: corn "in natura", kale, brown sugar, whole and refined wheat flour. One soil sample was also analysed to complete the study.

\subsection{Sampling and Preparation Procedures}

The food analysed are those mostly consumed in Minas Gerais state, Brazil. Corn cobs were randomly collected from a property located in the municipality of Biquinhas. The cobs were taken to the laboratory, and threshed. The grains were washed with tap and deionized water and then dried at room temperature.

Kale samples were collected from ten points in a vegetable garden in Nova Lima, and mixed as only one sample representative from the vegetable garden. The sampling was carried out during the wet season (February). The kale leaves were washed with deionised water and manually sliced in small pieces. The samples were frozen and then lyophilized.

Granulated and brown sugar, whole and refined wheat flour samples were randomly purchased in local 
M. Â. de B. C. Menezes et al., Neutron activation technique..., Rad. Applic., 2017, 2, 2, 124-128

market in Belo Horizonte. Aliquots of each sample were not submitted to any preparation.

The soil sample around $1 \mathrm{~kg}$ was collected from three sites in the same vegetable garden, as kale samples were collected. So, the soil sampling point was as deep as the vegetable roots. The sampling was carried out during the wet season (February). In the laboratory, the soil samples were air-dried, homogenized and sieved to five granulometric fractions. The finest-grained fraction of $<0.06 \mathrm{~mm}$ was analysed, since a finely ground soil $(<150 \mu \mathrm{m})$ is recommended [26] for the determination of the total metal contents.

Aliquots of all samples were weighed, around $200 \mathrm{mg}$, into polyethylene vials suitable for irradiation. For geological samples (soil and BCR-320R reference material), the volume of the vial was $0.30 \mathrm{~mL}$ and for biological samples (agro-industrial and GBW0805 samples), 0.51 mL.

\subsection{Irradiation and Gamma Spectrometry}

The irradiation was performed in the TRIGA MARK I IPR-R1 reactor located at CDTN (Nuclear Technology Development Centre)/CNEN (Nuclear Energy National Commission), at $100 \mathrm{~kW}$, under a thermal flux of $6.35 \times 10^{11} \mathrm{~cm}^{-2} \mathrm{~s}^{-1}$ for 8 hours. The irradiation was in the carrousel, IC-7, where the spectral parameters $f$ and $\alpha$ were: 22.32 and -0.0022, respectively [22]. The samples were simultaneously irradiated accompanied by the neutron flux monitor Al-0.1\%Au IRMM-530RA foil cut into discs (diameter of $5 \mathrm{~mm}$, thickness of $0.1 \mathrm{~mm}$ ).

To assure the effectiveness of the $k_{0}$-standardization method, the reference materials BCR-320R Channel Sediment from IRMM, Institute for Reference Materials and Measurements, Belgium, and GBW 0805, Tea, from Institute of Research, China were also analysed. The aliquots of these reference materials had the same shame and weigh of the samples analysed.

The gamma spectroscopy was carried out after the suitable decay and it was performed on an HPGe detector with 50\% relative efficiency and for the spectra analysis - peak area evaluation - the HyperLab program [27] was used. The software package Kayzero for Windows ${ }^{\circledR}$ [28] was applied to calculate the elemental concentrations.

\subsection{Quality Control}

Statistical tests can be applied to verify the analytical performance of the method and to perform the quality control. In this study, the $E_{\mathrm{n}}$ number [29] was calculated based on the results of reference materials analysed as they were samples, BCR-320R, Channel Sediment, and GBW 0805, Tea. These materials are similar matrices to the matrices studied. They were used because there are no reference materials for the samples analysed.

The $E_{\mathrm{n}}$-number considers the expanded uncertainty of the experimental analysis and the certified values of reference materials with a coverage factor of $k=2(95 \%$ confidence interval). The criterion of evaluation of the analytical response, indicating the performance of the method is $|\mathrm{En}| \leq 1$ if the performance of the method applied was satisfactory and $|\mathrm{En}|>1$ if the method performance was unsatisfactory.

Satisfactory performance of the method means that the method produced results with $95 \%$ of possibility to be within a range of values that correspond to the true values.

Table 1. Reference Materials BCR-320R and GBW0805: Experimental and Certified and Recommended Values and En-number

\begin{tabular}{|c|c|c|c|c|c|c|}
\hline \multirow[b]{2}{*}{$\mathrm{El}$} & \multicolumn{3}{|c|}{ BCR-320R (Channel Sediment), dry weight } & \multicolumn{3}{|c|}{ GBWo805 (Tea), dry weight } \\
\hline & $\begin{array}{c}(k=1) \\
\text { Experimental } \\
\text { Values } \\
(\mathrm{mg} / \mathrm{kg})\end{array}$ & $\begin{array}{c}(k=2) \\
\text { Certified } \\
\text { Values } \\
(\mathrm{mg} / \mathrm{kg})\end{array}$ & $\begin{array}{c}E_{\mathrm{n}^{-}} \\
\text {number }\end{array}$ & $\begin{array}{c}(k=1) \\
\text { Experimental } \\
\text { Values } \\
(\mathrm{mg} / \mathrm{kg})\end{array}$ & $\begin{array}{c}(k=2) \\
\text { Recommended } \\
\text { Values } \\
(\mathrm{mg} / \mathrm{kg})\end{array}$ & $\begin{array}{c}E_{\mathrm{n}^{-}} \\
\text {number }\end{array}$ \\
\hline As & $23 \pm 1$ & $21.7 \pm 2.0$ & +0.27 & $0.20 \pm 0.01$ & $0.191 \pm 0.025$ & +0.33 \\
\hline $\mathrm{Ba}$ & - & - & - & $14 \pm 1$ & $15 \cdot 7 \pm 2.4$ & -0.61 \\
\hline $\mathrm{Ca}$ & - & - & - & $3088 \pm 184$ & $2840 \pm 227$ & +0.57 \\
\hline $\mathrm{Ce}$ & - & - & - & 0.03 & $0.686 \pm 0.096$ & +0.69 \\
\hline Co & $10 \pm 1$ & $9.7 \pm 0.6$ & +0.25 & - & - & - \\
\hline $\mathrm{Cr}$ & $62 \pm 4$ & $59 \pm 4$ & +0.31 & - & - & - \\
\hline $\mathrm{Fe}$ & $26083 \pm 1780$ & $25700 \pm 1300$ & +0.10 & $390 \pm 10$ & $373 \pm 63$ & +0.26 \\
\hline $\mathrm{K}$ & - & - & - & $21010 \pm 537$ & $19700 \pm 1379$ & +0.75 \\
\hline $\mathrm{La}$ & - & - & - & $0.44 \pm 0.01$ & $0.458 \pm 0.023$ & -0.56 \\
\hline $\mathrm{Na}$ & - & - & - & $157 \pm 4$ & $142 \pm 14$ & +0.94 \\
\hline $\mathrm{Rb}$ & - & - & - & $39 \pm 1$ & $36.9 \pm 1.48$ & +0.70 \\
\hline $\mathrm{Sb}$ & - & - & - & $0.041 \pm 0.001$ & $0.037 \pm 0.0033$ & +0.98 \\
\hline $\mathrm{Sc}$ & $5.4 \pm 0.4$ & $5.2 \pm 0.4$ & +0.26 & - & - & - \\
\hline $\mathrm{Sr}$ & - & - & - & $13 \pm 1$ & $10.8 \pm 1.8$ & +0.80 \\
\hline $\mathrm{Th}$ & $5.2 \pm 0.5$ & $5 \cdot 3 \pm 0.4$ & -0.05 & $0.111 \pm 0.003$ & $0.105 \pm 0.013$ & +0.45 \\
\hline $\mathrm{U}$ & $1.4 \pm 0.1$ & $1.56 \pm 0.20$ & -0.34 & - & - & - \\
\hline
\end{tabular}

Note: - Not Recommended or Certified Values 
M. Â. de B. C. Menezes et al., Neutron activation technique..., Rad. Applic., 2017, 2, 2, 124-128

Table 2. Composition of Agro-Industrial products obtained by $k_{0}$-INAA. Uncertainty is given as combined standard uncertainty.

\begin{tabular}{|c|c|c|c|c|c|c|}
\hline \multirow[b]{2}{*}{ Element } & \multicolumn{6}{|c|}{ Elemental Concentration (dry weight) (mg kg-1) } \\
\hline & Kale & Corn & Whole Wheat Flour & Refined Wheat Flour & Brown Sugar & Soil \\
\hline As & $<0.05$ & $<0.008$ & $<0.06$ & $<0.06$ & $0.29 \pm 0.01$ & $0.25 \pm 0.03$ \\
\hline $\mathrm{Au}$ & $<0.05$ & $0.0003 \pm 0.0001$ & $<0.0003$ & $<0.0003$ & $0.0006 \pm 0.0001$ & $<0.001$ \\
\hline $\mathrm{Ba}$ & $<10$ & $<1.4$ & $5 \pm 1$ & $<4$ & $1.2 \pm 0.1$ & $<14$ \\
\hline $\mathrm{Br}$ & $1.9 \pm 0.1$ & $0.33 \pm 0.06$ & $6 \pm 0.2$ & $1.7 \pm 0.1$ & $2.7 \pm 0.1$ & $<4$ \\
\hline $\mathrm{Ca}$ & $<3000$ & $<220$ & $<200$ & $<200$ & $1726 \pm 283$ & $<200$ \\
\hline $\mathrm{Cd}$ & $<20$ & $<0.1$ & $<1$ & $<1$ & $<1$ & $<40$ \\
\hline $\mathrm{Ce}$ & $<1$ & $<1$ & $<0.2$ & $<0.2$ & $0.048 \pm 0.005$ & $<1$ \\
\hline Co & $<0.1$ & $0.0049 \pm 0.0006$ & $0.019 \pm 0.002$ & $0.020 \pm 0.002$ & $0.037 \pm 0.001$ & $0.28 \pm 0.04$ \\
\hline $\mathrm{Cr}$ & $<1$ & $<0.1$ & $<0.2$ & $<0.2$ & $0.70 \pm 0.03$ & $4.6 \pm 0.5$ \\
\hline Cs & $<0.1$ & $<0.005$ & $0.006 \pm 0.002$ & $0.014 \pm 0.001$ & $0.0067 \pm 0.0004$ & $<0.5$ \\
\hline $\mathrm{Eu}$ & $<0.1$ & $<0.1$ & $<0.003$ & $<0.003$ & $<0.1$ & $<1$ \\
\hline $\mathrm{Fe}$ & $<30$ & $13 \pm 1$ & $60 \pm 3$ & $85 \pm 4$ & $43 \pm 2$ & $1115 \pm 57$ \\
\hline $\mathrm{Hf}$ & $<0.1$ & $<0.1$ & $<0.01$ & $<0.01$ & $0.0080 \pm 0.0005$ & $<0.2$ \\
\hline $\mathrm{Hg}$ & $<0.1$ & $<0.03$ & $<0.1$ & $<0.1$ & $<0.01$ & $<2$ \\
\hline K & $5397 \pm 191$ & $(2.9 \pm 0.4)^{*}$ & $3151 \pm 111$ & $1675 \pm 60$ & $5044 \pm 177$ & $5764 \pm 203$ \\
\hline $\mathrm{La}$ & $<0.05$ & $<0.001$ & $<0.02$ & $<0.02$ & $0.019 \pm 0.001$ & $0.56 \pm 0.02$ \\
\hline $\mathrm{Mn}$ & $2.4 \pm 0.1$ & $<10$ & $34 \pm 1$ & $<10$ & $<10$ & $<200$ \\
\hline Mo & $<2$ & $0.26 \pm 0.01$ & $0.4 \pm 0.1$ & $<0.2$ & $<2$ & $<30$ \\
\hline $\mathrm{Na}$ & $118 \pm 7$ & $5.5 \pm 0.5$ & $75 \pm 3$ & $135 \pm 5$ & $10.5 \pm 0.4$ & $45 \pm 2$ \\
\hline $\mathrm{Rb}$ & $<0.5$ & $4.4 \pm 0.4$ & $2.1 \pm 0.1$ & $1.9 \pm 0.1$ & $4.9 \pm 0.2$ & $<6$ \\
\hline $\mathrm{Sb}$ & $<0.02$ & $<0.002$ & $0.008 \pm 0.001$ & $<0.005$ & $0.0083 \pm 0.0005$ & $<0.04$ \\
\hline Sc & $<0.001$ & $<0.003$ & $0.0023 \pm 0.0003$ & $0.0037 \pm 0.0002$ & $0.0036 \pm 0.0001$ & $0.11 \pm 0.01$ \\
\hline $\mathrm{Sm}$ & $<0.03$ & $<0.001$ & $<0.004$ & $<0.004$ & $0.0022 \pm 0.0002$ & $0.036 \pm 0.003$ \\
\hline $\mathrm{Sr}$ & $<20$ & $<3$ & $<5$ & $<5$ & $3.2 \pm 0.3$ & $<5$ \\
\hline $\mathrm{Ta}$ & $<0.001$ & $<0.003$ & $<0.005$ & $<0.005$ & $<0.005$ & $<0.1$ \\
\hline Th & $<0.01$ & $<0.01$ & $<0.01$ & $<0.01$ & $0.0039 \pm 0.0004$ & $<0.1$ \\
\hline U & $<0.1$ & $<0.01$ & $<0.06$ & $<0.06$ & $<0.1$ & $<1$ \\
\hline $\mathrm{Zn}$ & $3.6 \pm 0.2$ & $22 \pm 4$ & $21 \pm 1$ & $9.9 \pm 0.4$ & $30 \pm 3$ & $47 \pm 3$ \\
\hline
\end{tabular}

Notes: *, \%; < limit of detection for $k_{0}$-INAA, for this element in this sample

\section{RESUlts AND DisCUSSION}

Table 1 shows the experimental results obtained for BCR-320R and for GBW0805 and their certified and recommended values, respectively, and the $E_{\mathrm{n}}$-number obtained for these values. It is important to observe that all $\left|E_{\mathrm{n}}\right| \leq 1$. It means that the $k_{\mathrm{o}}$ standardization method produced all results within $95 \%$ of confidence interval for assigned values, pointing out satisfactory performance of the method.

Table 2 displays the elemental concentration results for agro industrial products analysed in this study. By applying the $k_{0}$-method, it was possible to determine several elements with a large range of concentrations.

\section{CONCLUSIONS}

This paper shows that neutron activation analysis, $k_{0}$-method, is a technique suitable to determine the mineral composition of agro-industrial products, determining several elements with a large range of concentrations, without any chemical procedure prior to the analysis.

The statistical test, $E_{\mathrm{n}}$-number, pointed out that the method is efficient, producing results within the $95 \%$ of confidence interval.
Acknowledgement: The authors would like to thank Brazilian institutions CAPES/CNPq and FAPEMIG for financial support and to CDTN/CNEN for allowing the development of this study in its facilities.

\section{REFERENCES}

1. W. Wardencki et al., "Instrumental techniques used for assessment of food quality," in Proceedings of ECOpole, 2009, pp. 273-279.

Retrieved from:

https://www.researchgate.net/publication/265307501 Instrumental techniques used for_assessment of $\mathrm{f}$ ood quality

Retrieved on: Feb. 2, 2017

2. J. Davídek, "Food Quality and Assurance," in Food Quality and Standards, vol. 2, R. Lasztity, Ed., Paris, France: EOLSS Publishers, 2009, pp. 1-25.

Retrieved from:

https://www.eolss.net/Sample-Chapters/C10/E5-0803-00.pdf

Retrieved on: Jan. 20, 2017

3. L. H. Jomaa et al., "Development of a standardized measure to assess food quality: a proof of concept," Nutrition Journal, vol. 15, no. 1, p. 96, Nov. 2016.

DOI: $10.1186 / \mathrm{s} 12937-016-0215-4$

PMid: 27829438

PMCid: PMC5103403

4. L. E. Rodriguez-Saona and M. E. Allendorf, "Use of FTIR for rapid authentication and detection of adulteration of food," Annu. Rev. Food Sci. Technol., vol. 2, pp. 467-483, 2011.

DOI: 10.1146/annurev-food-022510-133750 
M. Â. de B. C. Menezes et al., Neutron activation technique..., Rad. Applic., 2017, 2, 2, 124-128

PMid: 22129392

5. D. R. Abernethy et al., "Metal impurities in food and drugs," Pharmaceutical Research, vol. 27, no. 5, pp. 750-755, May 2010.

DOI: $10.1007 /$ s11095-010-0080-3

PMid: 20217462

6. J. M. Perkel, "Does this taste funny? The Technologies of Food Forensics," Science, vol. 332, no. 6037, pp. 1582-1584, Jun, 2011.

DOI: $10.1126 /$ science.332.6037.1582

7. M. de la Guardia, S. Garrigues, Handbook of Mineral Elements in Food, Chichester: Wiley-Blackwell, 2015. DOI: $10.1002 / 9781118654316$

8. H. Gallardo et al., "Possibilities of low-power X-ray fluorescence spectrometry methods for rapid multielemental analysis and imaging of vegetal foodstuffs," Journal of Food Composition and Analysis, vol. 50, pp. 1-9, Apr, 2016.

DOI: doi.org/10.1016/j.jfca.2016.04.007

9. A. L. de Oliveira et al., "Elemental contents in exotic Brazilian tropical fruits evaluated by energy dispersive X-ray fluorescence," Sci. Agric. (Piracicaba, Braz.), vol. 63, no. 1, pp. 82-84, Jan-Feb. 2006 DOI: $10.1590 /$ So103-90162006000100013

10. M. Waziri et al., "Elemental composition of 'Dalang': A food condiment from evaporated extract of Borassus aethiopum fruit ash," Am. J. Food. Nutr, vol. 1, no. 3, pp. 123-125, 2011.

DOI: 10.5251/ajfn.2011.1.3.123.125

11. Y. F. Huang et al., "Evaluation of essential and toxic elements concentrations in different parts of buckwheat," Czech J. Food Sci., vol. 31, no. 3, pp. 249255, 2013.

Retrieved from:

http://www.agriculturejournals.cz/publicFiles/92401.p $\underline{\mathrm{df}}$

Retrieved on: Feb. 3, 2017

12. E. P. Nardi et al., "The use of inductively coupled plasma mass spectrometry (ICP-MS) for the determination of toxic and essential elements in different types of food samples," Food Chemistry, vol. 112, no. 3, pp.727-732, Feb. 2009.

DOI: $10.1016 /$ j.foodchem.2008.06.010

13. D. K. Adotey et al., "Essential elements content in core vegetables grown and consumed in Ghana by instrumental neutron activation analysis," African Journal of Food Science, vol. 3, no. 9, pp. 243-249, Sep. 2009.

14. M. Bounakhla et al., "Instrumental neutron activation analysis for essential and toxic elements in Kenitra city (Morocco) foods," J. Radioanal. Nucl. Chem., vol. 282, no. 1, pp. 145-15o, Sep. 2009.

DOI: $10.1007 / \mathrm{s} 10967-009-0364-4$

15. D. De Soete, R. Gijbels, J. Hoste, Neutron Activation Analysis, New York (NY), USA: Wiley - Interscience, 1972.

16. P. M. B. Salles et al., "Inorganic elements in sugar samples consumed in several countries," J. Radioanal. Nucl. Chem., vol. 308, no. 2, pp. 485-493, May 2016. DOI: $10.1007 /$ s10967-015-4478-6

17. K. A. P. Oliveira et al., "Use of nuclear technique in samples for agricultural purposes," Engenharia Agrícola, vol. 33, no. 1, pp. 46-54, Jan-Feb. 2013.
DOI: 10.1590/So100-69162013000100006

18. M. A. Beinner et al., "Plasma zinc and hair zinc levels, anthropometric status and food intake of children in a rural area of Brazil," Revista de Nutrição, vol. 23, no. 1, pp. 75-83, Jan-Feb. 2010.

DOI: $10.1590 /$ S1415-52732010000100009

19. M. A. B. C. Menezes et al., "Iron Quadrangle, Brazil: Elemental concentration determined by $\mathrm{k}_{0}$-instrumental neutron activation analysis Part I: Soil samples," J. Radioanal. Nucl. Chem., vol. 270, no. 1, pp. 111-116, 2006.

DOI: $10.1007 / \mathrm{s} 10967-006-0316-1$

20. M. A. B. C. Menezes et al., "Iron Quadrangle, Brazil: Elemental concentration determined by $\mathrm{k}_{0}$-instrumental neutron activation analysis Part II: Kale samples," J. Radioanal. Nucl. Chem., vol. 270, no. 1, pp. 117-121, 2006.

DOI: $10.1007 / \mathrm{s} 10967-006-0317-0$

21. A. L. Maulvault et al., "Nutritional quality and safety of cooked edible crab (Cancer Pagurus)," Food Chem., vol. 133, no. 2, pp. 277-283, Jul. 2012.

DOI: doi.org/10.1016/j.foodchem.2012.01.023

PMid: 25683396

22. M. A. B. C. Menezes and R. Jaćimović, "Optimised $k_{0-}$ instrumental neutron activation method using the TRIGA MARK I IPR-R1 reactor at CDTN/CNEN, Belo Horizonte, Brazil," Nuclear Instruments and Methods in Physics Research Section A, vol. 564, no. 2, pp. 707715, Aug. 2006.

DOI: $10.1016 /$ j.nima.2006.04.013

23. F. De Corte, The $k_{o}$-standardization method: A move to the optimization of NAA, Habilitation Thesis, University of Ghent, Ghent, Belgium, 1987.

24. F. De Corte, A. Simonits, "Recommended nuclear data for use in the $k_{0}$ standardization of neutron activation analysis," Atomic Data and Nuclear Data Tables, vol. 85, no. 1, pp. 47-67, Sep. 2003.

DOI: $10.1016 /$ Soo92-640X(03)00036-6

25. R. Jaćimović et al., "The recommended $\mathrm{k}[\mathrm{sub}] \mathrm{o}$ database", Journal of Radioanalytical and Nuclear Chemistry, vol. 300, no. 2, pp. 589-592, May 2014. DOI: 10.1007/s10967-014-3085-2

26. B. J. Alloway, Heavy Metals in Soil, London, UK: Blackie Academy \& Professional, 1995 DOI: 10.1007/978-94-007-4470-7

27. HyperLabs Software, Budapest, Hungary, 1998-2013, HyperLab Gamma Spectroscopy Software. Retrieved from: http://hlabsoft.com/

Retrieved on: Jun. 9, 2011

28. Kayzero for Windows for reactor neutron activation analysis (NAA) using the $k_{o}$ standardization method: Version 2, DSM Research, Geleen, The Netherlands, 2011.

Retrieved from:

http://www.kayzero.com/KfW\%20Manual\%20V1.pdf Retrieved on: Apr. 2, 2017

29. Statistical methods for use in proficiency testing by interlaboratory comparisons. ISO 13528: 2005, 2005. 